\title{
Juniperus chinensis extract induces apoptosis via reaction oxygen species (ROS) generation in human pancreatic cancer cell lines
}

\author{
Boram Go ${ }^{1,3} \cdot$ Song-I Han ${ }^{2} \cdot$ Jungwhoi Lee ${ }^{2} \cdot$ Da-Hye Kim $^{1} \cdot$ Chang-Sook Kim $^{1}$ \\ - Jae Hoon Kim $^{1,2}$
}

Received: 29 September 2020 / Accepted: 6 December 2020 / Published Online: 31 December 2020

(C) The Korean Society for Applied Biological Chemistry 2020

\begin{abstract}
Pancreatic cancer is among the most difficult-to-treat tumors. More than half of patients with this cancer have very few symptoms at the early stages, allowing the development of distant metastases and resistance to cancer treatment. In this study, we found that Juniperus chinensis extract (JCX) decreased the cell viability and migration activity of PANC-1 and SNU-213 pancreatic cancer cells in a dose-dependent manner. JCX increased caspase3 activation and generation of reactive oxygen species (ROS). Nacetylcysteine treatment blocked JCX-induced ROS generation and the negative effects on pancreatic cancer cell viability. In addition, JCX down-regulated the levels of phospho-focal adhesion kinase (p-FAK) and phospho-extracellular signal-regulated kinase (p-ERK). Together, these results indicate that JCX induces apoptosis in human pancreatic cancer cell lines through ROS production, downregulating FAK/ERK signaling and activating caspase-3. We propose that JCX-derived compounds represent candidates for the development of alternative medicines for the treatment of pancreatic cancer.
\end{abstract}

Keywords Apoptosis - Cell viability · Juniperus chinensis . Migration · Pancreatic cancer $\cdot$ Rreactive oxygen species

Jae-Hoon $\operatorname{Kim}(\bowtie)$

E-mail:kimjh@jejunu.ac.kr

${ }^{1}$ Department of Biotechnology, College of Applied Life Science, SARI, Jeju National University, Jeju63243, Republic of Korea

${ }^{2}$ Subtropical/tropical organism gene bank, jeju National University, Jeju 63243, Republic of Korea

${ }^{3}$ Biodiversity Research Institute, Jeju Technopark, Jeju 63608, Republic of Korea

This is an Open Access article distributed under the terms of the Creative Commons Attribution Non-Commercial License (http://creativecommons. org/licenses/by-nc/3.0/) which permits unrestricted non-commercial use, distribution, and reproduction in any medium, provided the original work is properly cited.

\section{Introduction}

Pancreatic cancer is one of the most dangerous cancers: the 5-year survival rate is less than about $8 \%$, very low relative to other cancers. It has few early symptoms, and more than $50 \%$ of patients have developed distant metastases at the time of diagnosis [1]. Invasive pancreatic cancers are resistant to common cancer therapies such as chemotherapy and radiation therapy [2]. Accordingly, new strategies for the treatment of pancreatic cancer are in high demand.

Genus Juniperus is widely distributed in East Asian countries such as Korea, China, Japan, and Mongolia. Juniperus extracts have diverse physiological components, including flavones, lignans, and terpene $[3,4]$. These physiological components have antimicrobial, anti-bacterial, anti-insect, anti-viral, and anti-tumor activities [5-8]. For example, the leaf extract of Juniperus chinensis has a cytotoxic effect on two tumor cell lines, HeLa and HGC-27 [9].

Apoptosis differs from other types of cell death in that it progresses without inflammation. The process is under strict control and is strongly associated with biological processes such as aging, embryogenesis, and diseases. Reactive oxygen species (ROS) are metabolic byproducts that act on cell signaling and homeostasis, but a mismatch between the production of ROS and biological ROS removal results in oxidative stress. Excessively high levels of ROS cause apoptosis or necrosis [10,11]. ROS and oxidative stresses are involved in the regulation of signal transduction pathways associated with tumorigenesis. Some therapeutic strategies increase the level of intracellular ROS to induce damage to tumor cells and ultimately cause their death [12].

Here, we report that Juniperus chinensis extract (JCX) inhibits cell viability and migration in human pancreatic cancer cells. JCX increases intracellular ROS levels and regulates the FAK/ERK pathway and apoptosis-related proteins, suggesting that it could be used to develop substances for the treatment of pancreatic cancer. 


\section{Material and Methods}

\section{Sample preparation and antibodies}

Crude extract of Juniperus chinensis leaves was obtained from Biodiversity Research Institute, dissolved in 70\% ethanol, and passed through a $0.2 \mu \mathrm{m}$ syringe filter. Antibodies against phospho-tyrosine and GAPDH were purchased from Santa Cruz Biotechnology (Santa Cruz, CA, USA). Antibodies against phosphoFAK, FAK, phospho-ERK, ERK, caspase-3, cleaved caspase-3, and proliferating cell nuclear antigen (PCNA) were purchased from Cell Signaling Technology.

\section{Cell culture}

293T, PANC-1, and SNU-213 cells were obtained from the Korean Cell Line Bank (Seoul, Korea). 293T and PANC-1 cells were maintained in Dulbecco's modified Eagle's medium supplemented with $10 \%$ fetal bovine serum, $100 \mathrm{U} / \mathrm{mL}$ penicillin, and $100 \mu \mathrm{g} / \mathrm{mL}$ streptomycin. SNU-213 cells were maintained in RPMI-1640 medium containing 10\% fetal bovine serum, $25 \mathrm{mM}$ HEPES, $100 \mathrm{U} / \mathrm{mL}$ penicillin, and $100 \mu \mathrm{g} / \mathrm{mL}$ streptomycin. All cells were cultured in a humidified incubator at $37{ }^{\circ} \mathrm{C}$ and $5 \%$ $\mathrm{CO}_{2}$.

\section{Cell viability assay}

293T, PANC-1, and SNU-213 cells were seeded at a density of $1 \times 10^{4}$ cells/well in 24-well plates overnight and then treated with different concentrations $(0,2.5,5,7.5,10$, and $15 \mu \mathrm{g} / \mathrm{mL})$ of JCX for $72 \mathrm{~h}$. Pretreatment with N-acetylcysteine (NAC) was performed $1.5 \mathrm{~h}$ prior to treatment with JCX. Cell viability was assessed by WST assay (EZ-Cytox, DoGenBio, Seoul, Korea). Fifty microliters of WST solution was added to each well, and the samples were incubated for $30 \mathrm{~min}$ at $37^{\circ} \mathrm{C}$. Absorbance was measured on a microplate reader (ScanIt, BD Biosciences, San Jose, CA, USA) at $450 \mathrm{~nm}$.

Cell viability $=(\mathrm{OD}($ sample $)) /(\mathrm{OD}$ (average of control $))$

\section{Scratch wound healing assay}

PANC-1 and SNU-213 cells were incubated overnight by plating $5 \times 10^{5}$ cells/well in 6-well plates, and then the medium was replaced with $0.5 \%$ FBS medium (PANC-1) or $0.75 \%$ FBS medium (SNU-213 cells) for an additional $24 \mathrm{~h}$ incubation. Confluent monolayer cells were wounded manually with scratchers (SPL Life Science, Pochen, Korea), washed twice with PBS, and then incubated with fresh medium containing $\operatorname{JCX}(0,10 \mu \mathrm{g} / \mathrm{mL})$ for $24 \mathrm{~h}$. At 0 and $24 \mathrm{~h}$, the wounded area was photographed under a microscope and measured using ImageJ.

Wound healing rate $=1-($ remained area $(24 \mathrm{~h})) /($ wounded area $(0 \mathrm{~h}))$

\section{Western blot assay}

293T, PANC-1, and SNU-213 cells were treated with $\operatorname{JCX}(0,10$ $\mu \mathrm{g} / \mathrm{mL}$ ) for $48 \mathrm{~h}$. Total proteins were extracted with M-PER lysis buffer (Thermo Science) containing protease inhibitors: 1× complete protease inhibitor cocktail (Roche), $2 \mathrm{mM}$ sodium vanadate, $30 \mathrm{mM}$ sodium pyrophosphate, and $100 \mathrm{mM}$ sodium fluoride. After heating at $95{ }^{\circ} \mathrm{C}$ for $5 \mathrm{~min}$, equal quantities of proteins were separated by $12 \%$ SDS-PAGE and transferred onto a nitrocellulose blotting membrane (GE Healthcare Life Science, Solingen, Germany). Membranes were blocked with 5\% BSA in TBST and incubated with primary antibodies $(1: 1,000)$ overnight at $4{ }^{\circ} \mathrm{C}$. After washing with TBST, membranes were incubated with the corresponding secondary antibodies $(1: 4,000)$ at room temperature for $3 \mathrm{~h}$. Protein bands were detected using an ECL kit (Biosesang, Seoul, Korea) and recorded on X-ray film (AGFA).

\section{Flow cytometry analysis}

For analysis of apoptosis, 293T, PANC-1, and SNU-213 cells $\left(1 \times 10^{5}\right.$ cells/well $)$ were seeded in 6 -well plates overnight and treated with JCX ( 0 and $10 \mu \mathrm{g} / \mathrm{mL}$ ) for $72 \mathrm{~h}$. Cells were collected through trypsinization and washed with PBS. Next, the cells were incubated in the dark for $15 \mathrm{~min}$ with PI and Annexin V-FITC (FITC-Annexin V apoptosis detection kit, BD PharMingen, San Diego, CA, USA). Apoptotic cells were analyzed by flow cytometry (LSRFortessa, BD Biosciences). For measurement of intercellular ROS, PANC-1 and SNU-213 cells $\left(1.5 \times 10^{5}\right.$ cells/well $)$ were plated in 12-well plates overnight, pretreated with NAC ( 0 and 10 $\mathrm{mM})$ for $1.5 \mathrm{~h}$, and then treated with $\operatorname{JCX}(0$ and $10 \mu \mathrm{g} / \mathrm{mL})$ for $6 \mathrm{~h}$. Cells were harvested and stained with $10 \mu \mathrm{M}$ H2DCF-DA (ROS detection reagent, Invitrogen, CA, Carlsbad, USA) in the dark for $15 \mathrm{~min}$. Intracellular ROS measurement was conducted by flow cytometry.

\section{Statistical analysis}

Data were presented as averages \pm standard deviation (SD). Differences among multiple groups were analyzed using Tukey's post hoc method. $p<0.05$ was regarded as statistically significant.

\section{Results}

Juniperus chinensis extract (JCX) decreases cell viability in human pancreatic cancer cell lines

We examined the effect of JCX on the viability of 293T, Panc-1, and SNU-213 pancreatic cancer cells using the WST assay (Fig. 1). All three cell lines were treated with various concentrations $(0$, $2.5,5,7.5,10$, and $15 \mu \mathrm{g} / \mathrm{mL}$ ) of JCX for $72 \mathrm{~h}$. JCX treatment decreased cell viability in a dose-dependent manner. JCX had a stronger effect in PANC-1 and SNU-213 human pancreatic cancer cells than in control $293 \mathrm{~T}$ cells, which are derived from human embryonic kidney. Treatment with $10 \mu \mathrm{g} / \mathrm{mL}$ JCX decreased cell viability by $120 \pm 6.97,44.0 \pm 5.30$, and $33.65 \pm 7.06 \%$ in $293 \mathrm{~T}$, Panc-1, and SNU-213 cells, respectively. 
(A)

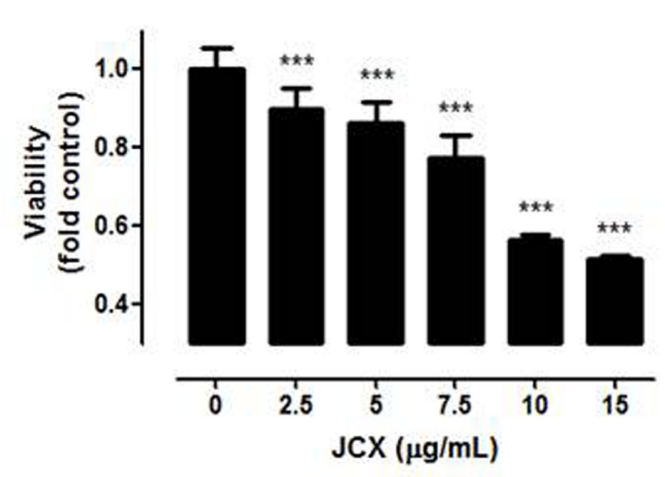

(C)

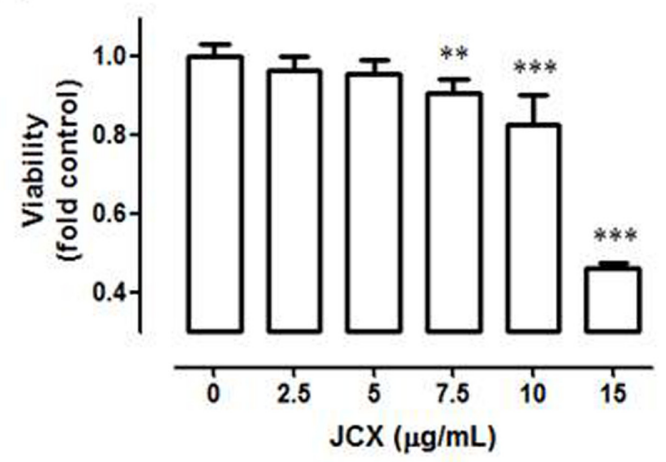

(B)

SNU-213

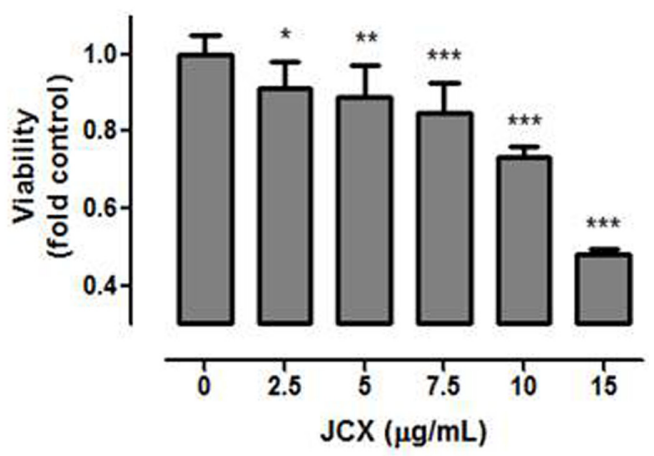

Fig. 1 Effects of various concentrations of JCX on viability of human pancreatic cancer cells. (A-B) Panc-1 and SNU-213 human pancreatic cancer cells, and (C) 293T human embryonic kidney cells were treated with various concentrations $(0,2.5,5,7.5,10$, and $15 \mu \mathrm{g} / \mathrm{mL})$ of JCX for $72 \mathrm{~h}$. Cell viabilities were measured by WST assay. Each point represents the mean \pm SD $\left({ }^{*} p<0.05,{ }^{* *} p<0.01, * * * p<0.001\right)$. (D) PANC-1, SNU213, and 293T cells were treated with JCX for $48 \mathrm{~h}$

intracellular ROS levels in PANC-1 (17.1\%) and SNU-213 cells (14.2\%), but not in 293 T cells. NAC treatment lowered the ROS levels of cells. Pretreatment with NAC inhibited the JCXmediated loss of viability in a dose-dependent manner (Fig. 4B).

\section{Discussion}

Cancer cells acquire properties distinct from those of normal cells, making them resistant to apoptosis, which is an important consideration for anticancer therapy. Cancer cells avoid apoptosis by inducing anti-apoptotic mechanisms and/or by downregulating the pro-apoptotic program [13]. To date, however, the induction of apoptosis by JCX in pancreatic cancer cell lines has not been investigated.

In this study, we found that JCX decreased viability in a dosedependent manner in human pancreatic cancer cells. Treatment with $10 \mu \mathrm{g} / \mathrm{mL}$ JCX slightly reduced cell viability by approcimately $12 \%$ in control $293 \mathrm{~T}$ cells, but significantly reduced cell viability by approximately 44 and 34\% in Panc- 1 and SNU-213 cells. The up-regulation of cleaved (active) caspase- 3 and the down-regulation of PCNA demonstrated that JCX induced apoptosis. Caspase-3 plays a role in controlling the execution of apoptosis, and PCNA is essential for DNA replication. Focal adhesion kinase (FAK) is a non-receptor kinase localized to focal adhesions [14]. Extracellular JCX for 6 h. As shown in Fig. 4A, treatment with JCX increased 
(A)
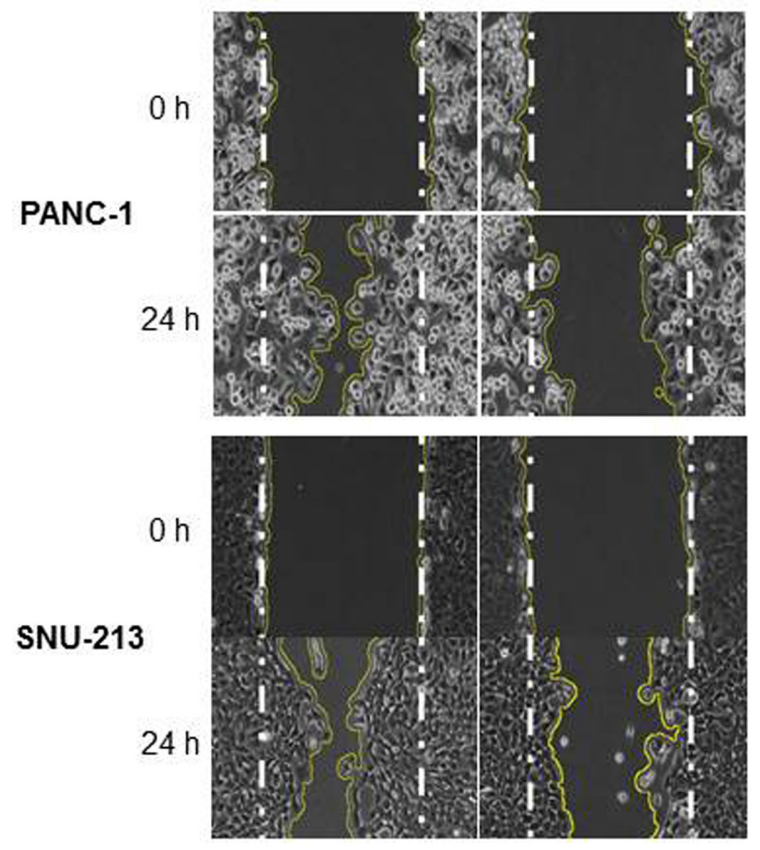

$J C X(\mu \mathrm{g} / \mathrm{mL})$
(B)

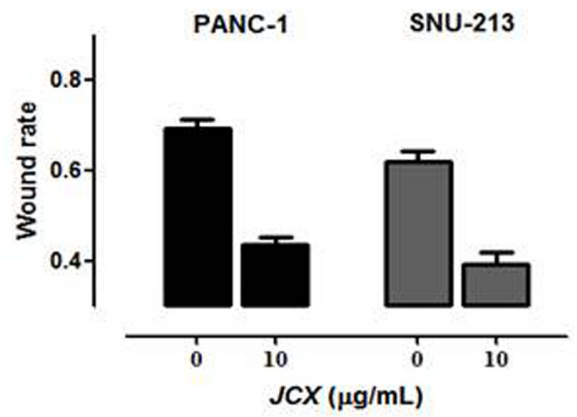

(C)

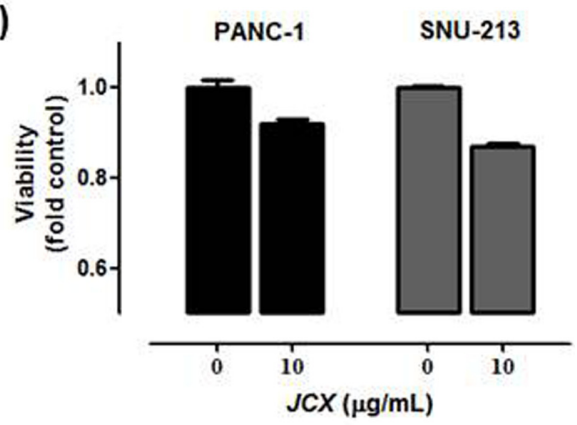

Fig. 2 Effects of various concentrations of JCX on migration of human pancreatic cancer cells. (A) Migration of Panc-1 and SNU-213 cells was monitored by wound healing assay. (B) Wound area was calculated from a representative of at least three independent experiments. (C) Cell viabilities were measured by WST assay

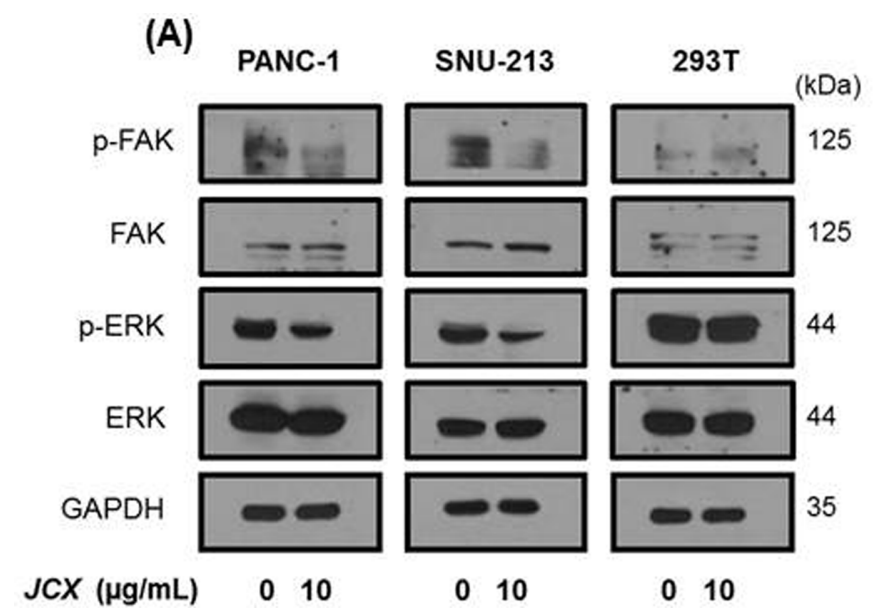

(B)

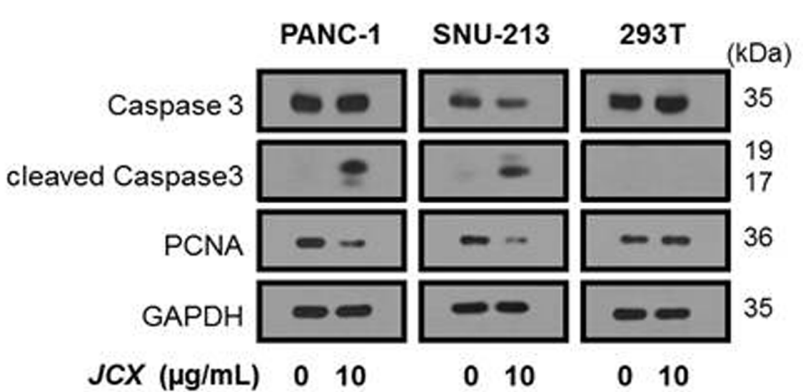

Fig. 3 Intracellular signaling by JCX in human pancreatic cancer cells. (A) Panc-1, SNU-213, and 293T cells were treated with JCX for 48 h, and the lysates were subjected to western blot analysis using antibodies for p-FAK, FAK, p-ERK, ERK, and GAPDH. (B) Expression of caspase-3, cleaved caspase-3, PCNA, and GAPDH

signal-regulated protein kinases $1 / 2$ (ERK1/2) are members of the superfamily of mitogen-activated protein kinases. The regulation of FAK/EKR modulates cell proliferation, migration, adhesion, apoptosis, and differentiation [15-17].

The anticancer effect of JCX was revealed in a previous study, which showed that it inhibits TPA-induced phospholipid formation in HeLa cells [9]. Widdrol from JCX induces apoptosis by promoting proteolytic cleavage of PARP and activation of AMPactivated protein kinase (AMPK) in HT29 colon adenocarcinoma cells $[18,19]$. Overexpression of FAK blocks caspase-3-mediated apoptosis, whereas inhibition of FAK induces AMPK activation $[20,21]$. We found that JCX inhibits cell viability and migration 
(A)

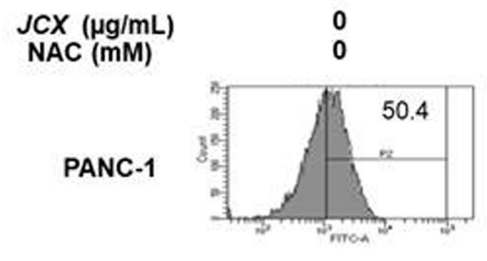

SNU-213

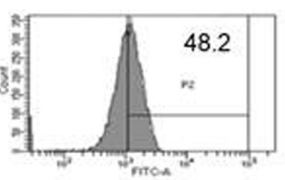

$293 \mathrm{~T}$
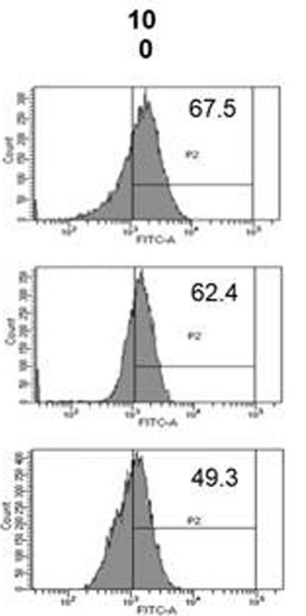
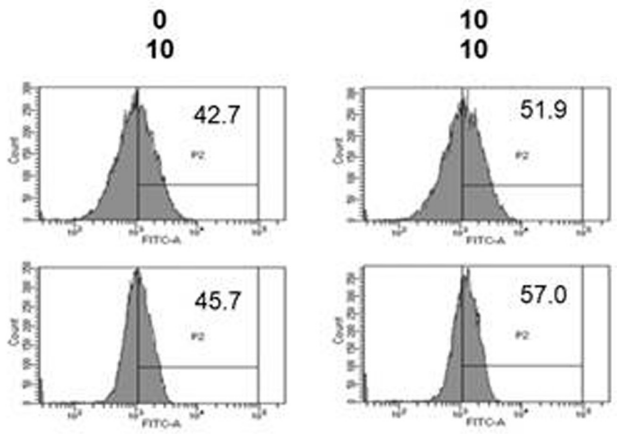

(B)
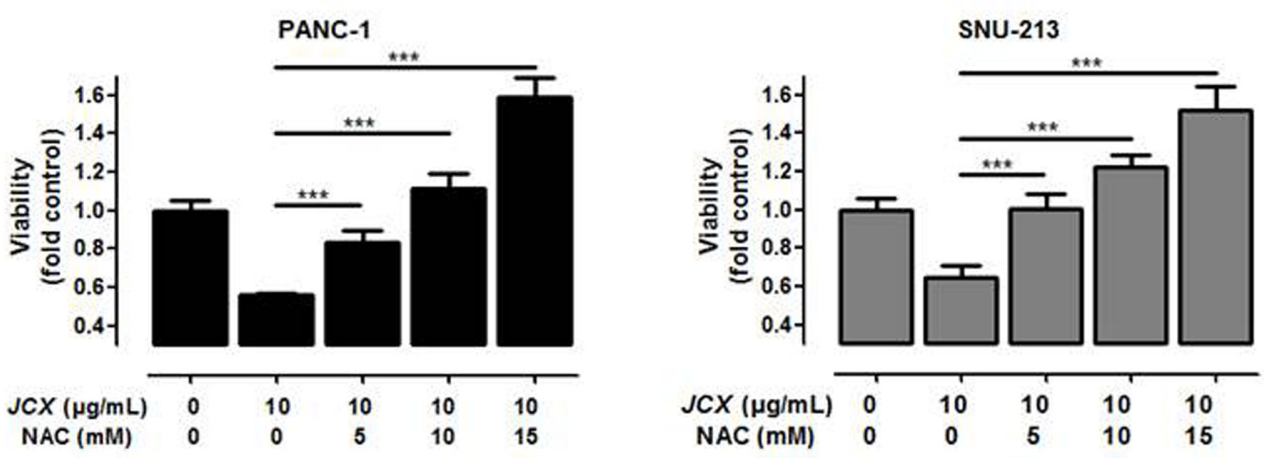

Fig. 4 Generation of reactive oxygen species (ROS) in human pancreatic cancer cells treated with JCX. (A) Flow cytometry assay of ROS generation under various concentrations of JCX. (B) NAC offsets the effect of JCX on viability. Cells were pretreated with NAC or vehicle prior to treatment with JCX. PANC-1 and SNU-213 cells were incubated with JCX for $72 \mathrm{~h}$. Cell viabilities were measured by WST assay. Each point represents the mean \pm SD. ${ }^{*} p<0.05,{ }^{* *} p<0.01,{ }^{* * *} p<0.001$

via downregulating p-FAK in pancreatic cancer cells. Our results with previous research suggest that the point of action of JCX (including widdrol) lies upstream of AMPK, or alternatively that other functional substances are present in JCX. Through GC/MS analysis, we found that 2-methoxy-4-vinylphenol is contained in JCX (data not shown). 2-Methoxy-4-vinylphenol is known to inhibit pancreatic cancer metastasis [25].

ROS is a mediator in the regulation of cell signaling. However, excessive ROS levels cause extreme oxidative stress in pancreatic cancer cells, eventually leading to apoptosis [15]. Substances such as epigallocate-3-gallate from tea, capsaicin from pepper, and benzyl isothiocynanate from papaya seeds share a similar mechanism of inducing apoptosis by increasing intracellular ROS levels [22-24]. Our study also revealed that the JCX-mediated effects on viability and migration generation in human pancreatic cancer cells are associated with ROS, and that pretreatment with NAC, a ROS scavenger, offsets the inhibitory effect of JCX. These findings are expected not only to enable the development of alternative anticancer agents based on JCX, but also to accelerate the study of the functional substances contained in JCX.
Acknowledgment This work was supported by the Basic Science Research Program through the National Research Foundation of Korea (NRF), funded by the Ministry of Education (2019R1F1A1063820). This research was supported by the 2019 scientific promotion program funded by Jeju National University.

\section{References}

1. Siegel RL, Miller KD, Jemal A (2018) Cancer statistics. CA Cancer J Clin 68(1): 7-30, doi: 10.3322/caac.21442

2. Samulitis BK, Pond KW, Pond E, Cress AE, Patel H, Wisner L, Patel C, Dorr RT, Landowski TH (2015) Gemcitabine resistant pancreatic cancer cell lines acquire an invasive phenotype with collateral hypersensitivity to histone deacetylase inhibitors. Cancer Biol Ther 16(1): 43-51, doi: $10.4161 / 15384047.2014 .986967$

3. Kuo YH, Chen WC (1994) Three new diterpenes, 1, 3-dioxototarol, isototarolenone, and 1-oxo-3 $\beta$-hydroxytotarol, form the roots of juniperus chinensis linn. Chem Pharm Bull (Tokyo) 42(9): 1774-1776

4. Lee CK, Fang JM, Cheng YS (1995) Norditerpenes from juniperus chinensis. Phytochemistry 39(2): 391-394

5. Ohashi H, Asai T, Kawai S (1994) Screening of main japanese conifers for antifungal leaf components, sesquiterpenes of juniperus chinensis var. Pyramidalis. Holzforschung 48(3): 193, doi: 10.1515/hfsg.1994.48.3.193 
6. Clark AM, McChesney JD, Adams RP(1990) Antimicrobial properties of heartwood, bark/sapwood and leaves of juniperus species. Phytotherapy Research 4(1): 15-19, doi: 10.1002/ptr.2650040105

7. Feliciano AS, Gordaliza M, del Corral JMM, Castro MA, GarcíaGrávalos MD, Ruiz-Lázaro P (1993) Antineoplastic and antiviral activities of some cyclolignans. Planta Med 59(03): 246-249, doi: $10.1055 / \mathrm{s}-2006-959660$

8. Tammami B, Torrance SJ, Cole JR (1977) Antitumor agent from juniperus bermudiana (pinaceae): Deoxypodophyllotoxin. Phytochemistry 16: 1100-1101

9. Ali AM, Mackeen MM, Intan-Safinar I, Hamid M, Lajis NH, ElSharkawy SH,Murakoshi M (1996) Antitumour-promoting and antitumour activities of the crude extract from the leaves of juniperus chinensis. J Ethopharmacol 53(3): 165-169, doi: 10.1016/03788741(96)01434-1

10. Martindale JL, Holbrook NJ (2002) Cellular response to oxidative stress: Signaling for suicide and survival*. J Cell Physiol 192(1): 1-15, doi: 10.1002/jep.10119

11. Diehn M, Cho RW, Lobo NA, Kalisky T, Dorie MJ, Kulp AN, Qian D, Lam JS, Ailles LE, Wong M, Joshua B, Kaplan MJ, Wapnir I, Dirbas FM, Somlo G, Garberoglio C, Paz B, Shen J, Lau SK, Quake SR, Brown JM, Weissman IL, Clarke MF (2009) Association of reactive oxygen species levels and radioresistance in cancer stem cells. Nature 458(7239): 780-783, doi: 10.1038/nature07733

12. Hanahan D, Weinberg RA: The hallmarks of cancer (2000) Cell 100(1): 57-70, doi: 10.1016/s0092-8674(00)81683-9

13. Fernald K, Kurokawa M (2013) Evading apoptosis in cancer. Trends Cell Biol 23(12): 620-633, PMID: 4091735, doi: 10.1016/j.tcb.2013. 07.006

14. Zachary I (1997) Focal adhesion kinase. Int J Biochem Cell Biol 29(7): 929-934 doi: 10.1016/s1357-2725(97)00008-3

15. Zhao J, Guan JL (2009) Signal transduction by focal adhesion kinase in cancer. Cancer Metastasis Rev 28(1-2): 35-49, doi: 10.1007/s10555-0089165-4

16. McLean GW, Carragher NO, Avizienyte E, Evans J, Brunton VG, Frame MC (2005) The role of focal-adhesion kinase in cancer-a new therapeutic opportunity. Nature Reviews Cancer 5(7): 505-515, doi: 10.1038/ nrc 1647
17. Mebratu Y, Tesfaigzi Y (2009) How erk1/2 activation controls cell proliferation and cell death: Is subcellular localization the answer? Cell Cycle 8(8): 1168-1175, doi: 10.4161/cc.8.8.8147

18. Kwon H-J, Lee E-W, Hong Y-K, Yun H-J, Kim B-W: Widdrol from juniperus chinensis induces apoptosis in human colon adenocarcinoma ht29 cells. Biotechnology and Bioprocess Engineering 15(1): 167-172, doi: 10.1007/s12257-009-0154-4

19. Kang MR, Park S-K, Lee CW, Cho IJ, Jo YN, Yang JW, Kim J-A, Yun J, Lee KH, Kwon HJ, Kim BW, Lee K, Kang JS, Kim HM (2012) Widdrol induces apoptosis via activation of amp-activated protein kinase in colon cancer cells. Oncol Rep 27(5): 1407-1412, doi: 10.3892/ or.2012.1644

20. Kamarajan P, Kapila YL (2007) An altered fibronectin matrix induces anoikis of human squamous cell carcinoma cells by suppressing integrin alpha $\mathrm{v}$ levels and phosphorylation of fak and erk. Apoptosis 12(12): 2221-2231, doi: 10.1007/s10495-007-0138-9

21. Tan X, Xu A, Zhao T, Zhao Q, Zhang J, Fan C, Deng Y, Freywald A, Genth H, Xiang J (2018) Simulated microgravity inhibits cell focal adhesions leading to reduced melanoma cell proliferation and metastasis via fak/rhoa-regulated mtorc1 and ampk pathways. Scientific Reports 8(1): 3769, doi: 10.1038/s41598-018-20459-1

22. Zhang R, Humphreys I, Sahu RP, Shi Y, Srivastava SK (2008) In vitro and in vivo induction of apoptosis by capsaicin in pancreatic cancer cells is mediated through ros generation and mitochondrial death pathway. Apoptosis 13(12): 1465-1478, doi: 10.1007/s10495-008-0278-6

23. Qanungo S, Das M, Haldar S, Basu A (2005) Epigallocatechin-3-gallate induces mitochondrial membrane depolarization and caspase-dependent apoptosis in pancreatic cancer cells. Carcinogenesis 26(5): 958-967, doi: 10.1093/carcin/bgi040

24. Sahu RP, Zhang R, Batra S, Shi Y, Srivastava SK (2009) Benzyl isothiocyanate-mediated generation of reactive oxygen species causes cell cycle arrest and induces apoptosis via activation of mapk in human pancreatic cancer cells. Carcinogenesis 30(10): 1744-1753, doi: 10.1093/ carcin/bgp157

25. Kim D-H, Han S-I, Go B, Oh U-H, Kim C-S, Jung Y-H, Lee J, Kim J-H (2019) 2-Methoxy-4-vinylphenol attenuates migration of human pancreatic cancer cells via blockade of FAK and AKT Signaling. Anticancer Res 29(12): 6695-6691, doi: 10.21873/anticanres.13883 